\title{
Modulation of mammary gland development in pre-pubertal mice as affected by soya and milk protein supplements
}

\author{
Brenda Alston-Mills ${ }^{1 *}+$ J. J. Lepri ${ }^{2}$ and C. A. Martin ${ }^{3}$ \\ ${ }^{1}$ North Carolina State University, Raleigh, NC 27695, USA \\ ${ }^{2}$ Department of Biology, University of North Carolina at Greensboro (UNCG), Greensboro, NC, USA \\ ${ }^{3}$ Behavioral Neuroscience Program, Department of Psychology, Michigan State University, East Lansing, MI 48824, USA \\ (Received 6 September 2010 - Revised 5 January 2011 - Accepted 7 January 2011 - First published online 9 March 2011)
}

\begin{abstract}
The objective of the present study was to determine the effects of soya and whey milk protein, $\alpha$-lactalbumin ( $\alpha$-LA), on mammary gland morphology and the structural support of the gland, in pre-pubertal mice after $7 \mathrm{~d}$ of treatment. In Expt 1, weaned (day 21) CD1 mice were given one of the four treatments, three included dietary supplements: (1) control diet, casein, (2) soya, (3) $\alpha$-LA and (4) subcutaneous injection of $2.5 \mu \mathrm{g}$ oestradiol benzoate in $20 \mu \mathrm{l}$ maize oil and fed the control diet. All diets were isoenergetic with equal protein concentrations. All groups that were not treated with oestradiol received the vehicle. Whole-mount analyses were performed to determine longitudinal ductal growth and terminal end bud development. DNA was extracted from the gland and assessed by spectrophotometry $(260 / 280 \mathrm{~nm})$. Tissue extracts for extracellular matrix (ECM) proteins, matrix metalloproteinase-2 $\left(\mathrm{MMP}_{2}\right)$, tissue inhibitor of $\mathrm{MMP}_{2}$ $\left(\mathrm{TIMP}_{2}\right)$, and serum oestradiol and mammary tissue epidermal growth factors (EGF) were measured by immunoassays. Expt 2 utilised the Her2/neu transgenic strain, with the same protocols. Statistical significance was determined by one-way ANOVA. From Expt 1 and 2 , soya and $\alpha$-LA significantly increased ductal elongation when compared with the oestrogen and control groups. These results were corroborated by data on total DNA and the ratio of $\mathrm{MMP}_{2}$ :TIMP 2 . The ratio of $\mathrm{MMP}_{2}$ :TIMP 2 was affected by $\alpha$-LA. Serum oestradiol was decreased only in the oestradiol-treated groups in both experiments. Soya is known to be oestrogenic and can act on epithelia directly. The mechanism by which $\alpha$-LA affects glandular development is by modulating the ECM or by promoting the synthesis/activity of EGF.
\end{abstract}

Key words: $\alpha$-Lactalbumin: Soya: Mouse mammary development: Extracellular matrix

There are many studies relating to the low incidence of breast cancer in Asian women and the link to the high intake of dietary soya foods, particularly during the early years of life ${ }^{(1,2)}$. Epidemiological studies in humans as well as animals have shown that the period of adolescence or pre-puberty is a sensitive period for the later occurrence of breast cancer ${ }^{(3)}$. Dietary supplements, many with unproven effectiveness, have become popular remedies against many forms of cancer. In post-menopausal women, soya is often recommended as an alternative to hormone replacement therapy. Contrary to the protective benefits of soya products, research has linked dietary isoflavones found in soya to oxidative DNA damage, thereby promoting tumour development in oestrogen-sensitive organs such as the uterus ${ }^{(4)}$. For example, genistein, the major isoflavone in soya, increases the incidence of hormone-dependent tumours in ovariectomised rats ${ }^{(5)}$.
Genistein is believed to enhance tumour development by increasing the rate of epithelial proliferation in the normal human breast in both pre- and post-menopausal women. Additionally, stimulation of breast secretion and growth of hyperplastic epithelial cells have been noted after soya intake $^{(6)}$. An example of the contradictory nature of studies done using soya isoflavones can be seen below. Thus, the effects of soya and isoflavones on breast tissue are not well defined $^{(7)}$.

Another line of research focuses on the consumption of dairy products and its relationship to breast cancer. In animal models, dairy products, including whey proteins, are protective against chemically induced mammary cancers. Reports have shown that dietary intake of whey or protein hydrolysates during the period of pre-pubertal development decreased the incidence of chemically induced mammary

Abbreviations: $\alpha$-LA, $\alpha$-lactalbumin; ECM, extracellular matrix; EGF, epidermal growth factor; MMP, matrix metalloproteinase; TEB, terminal end buds; TIMP, tissue inhibitor of metalloproteinases.

*Corresponding author: B. Alston-Mills, fax +1 517353 5278, email alstonmi@anr.msu.edu

† Present address: Michigan State University, 113 Agriculture Hall, East Lansing, MI 48824, USA. 
cancers in rats ${ }^{(8)}$. One hypothesis is that components in whey protein hydrolysates stimulate precocious maturation of the regions of the mammary gland that are most susceptible to neoplastic development ${ }^{(9)}$. In 1996, a longitudinal study followed up human subjects, demonstrating that those participants who regularly consumed milk as children had decreased incidence of breast cancer ${ }^{(10)}$. Milk consumption as a child was negatively correlated with subsequent breast cancer in young women 34-39 years of age ${ }^{(11)}$. In vitro studies using the whey milk protein $\alpha$-lactalbumin ( $\alpha$-LA) have supported these findings, showing that the protein can modulate activity at the cellular and tissue levels ${ }^{(12-14)}$ and decrease cell division in normal and transformed cell lines. Based on these results, we initially examined skimmed milk supplementation to the diets of newly weaned (day 21) female rats. At day 45, the chemical carcinogen 7,12-dimethylbenz(a)anthracene was administered, and the tumour incidence was compared with those of rats fed a soya and a control diet, with casein as its protein source. We observed that rats fed skimmed milk had significantly fewer tumours than the control or the soya-fed groups (EJ Hudson and $\mathrm{B}$ Alston-Mills, unpublished results). These results have been corroborated by more recent studies ${ }^{(15)}$.

The undifferentiated terminal ductal lobular unit in women, called the lobulaveolar unit in mice, is believed to include the stem cells that give rise to cancers, thus making this tissue of potential importance for determining susceptibility to tumorigenesis $^{(16,17)}$. Overall cell activity depends not only on cellcell associations but also on cell-stromal interactions ${ }^{(18)}$. Cells removed from an organism and cultured on plastic became morphologically and functionally undifferentiated, implying an important relationship or cross-talk between cell development and the surrounding extracellular matrix (ECM). This cross-talk is through signalling within the ECM, which in turn coordinates signalling among the epithelial cells ${ }^{(19)}$. While the ECM mediates normal cell behaviour, disruptions of the matrix have been implicated as a major factor in tumour development and progression ${ }^{(20,21)}$. It is well known that hormones and other local regulators such as epidermal growth factors (EGF) can modulate the activity of the ECM. As the ECM is altered, it facilitates changes in the mammary epithelial cells ${ }^{(22)}$. In theory, stabilising the ECM may contraindicate epithelial changes, leading to tumour development.

The mouse mammary tumour virus-neu/ErbB-2 (Her2/neu) transgenic mouse develops spontaneous mammary tumours with a long latency (approximately 5-6 months) because of overexpression of the neu proto-oncogene ${ }^{(23)}$. Overexpression of neu/ErbB has been reported to occur in $20-40 \%$ of human cancers $^{(24)}$. Studies have shown that in the mouse mammary tumour virus-neu mouse, soya isoflavones can delay tumour onset, without affecting tumour number or size ${ }^{(25)}$. Therefore, this mouse model offers an opportunity to examine mammary gland development in response to dietary intervention. We hypothesise that the protein components present in diets fed to pre-pubertal mice can alter the morphology of the gland and the regulatory ECM proteins by perturbing normal glandular growth patterns.

\section{Materials and methods}

\section{Expt 1}

Female CD1 mice (Charles River Laboratories, Wilmington, MA, USA) were weaned at $21 \mathrm{~d}$ of age and housed individually in standard cages with dimensions of $29 \cdot 21 \times 19.05 \times 12.70 \mathrm{~cm}$ fitted with wire lids and a substrate of sawdust on the floor of the cage. All mice were provided ad libitum access to drinking-water. The light-dark cycle was maintained at $12-12 \mathrm{~h}$ throughout the experiment, and the room temperature was regulated at $22^{\circ} \mathrm{C}$. Animals were weighed before (day 21) and after (day 28) the treatment. All procedures were done in accordance with the National Institutes of Health Guide for the Care and Use of Laboratory Animals, and were reviewed and approved by the North Carolina State University Animal Care and Use Committee. Treatment diets were formulated to be isoenergetic and with equal protein (Dyets, Inc., Bethlehem, PA, USA) (Table 1). At weaning, female pups from the normal strain of CD1 mice were randomly assigned to one of the four treatment groups: (1) normal casein-based chow as a negative control ( $n$ 30), (2) normal chow and daily subcutaneous injections of $2.5 \mu \mathrm{g}$ oestradiol benzoate (Sigma, St Louis, MO, USA) in $20 \mu \mathrm{l}$ maize oil ( $n$ 30), (3) chow with an $\alpha$-LA supplement ( $n$ 30) and (4) chow with a soya protein supplement ( $n 30)$. The left or right inguinal mammary glands were excised and fixed for whole-mount preparations, while abdominal glands were used for evaluations of total DNA and proteins. Whole glands were spread onto slides and fixed in Carnoy's fixative, hydrated through a series of alcohols followed by carmine-alum staining and dehydrated through a series of alcohols which is a slight modification of published procedures ${ }^{(26)}$. Mammary fat pad invasion was determined by the longitudinal growth from the nipple with respect to the lymph node using a double-blind scoring system by two evaluators. The standard used for

Table 1. Dietary constituents

\begin{tabular}{lccc}
\hline & Control diet & $\alpha$-Lactalbumin & Soya diet \\
\hline $\begin{array}{l}\text { Ingredients (g/kg) } \\
\text { Casein, high nitrogen }\end{array}$ & 200.00 & & \\
Lactalbumin & & 200.00 & \\
Isolated soya protein & & & 200.00 \\
$\quad$ Maize starch & 397.486 & 397.386 & 395.406 \\
Dyetrose & 132.00 & 132.00 & 132.00 \\
Sucrose & 90.00 & 100.00 & 100.00 \\
Cellulose & 50.00 & 50.00 & 50.00 \\
Soyabean oil & 70.00 & 70.00 & 70.00 \\
$t$-Butylhydroquinone & 0.014 & 0.014 & 0.014 \\
Salt mix no. 210025 & 35.00 & & \\
Salt mix no. 210040 & & 35.00 & \\
Salt mix no. 210037 & 10.00 & 10.00 & 10.00 \\
Vitamin mix no. 310025 & 3.00 & 2.10 & 2.54 \\
L-Cys & 2.50 & 2.50 & 2.50 \\
Choline bitartrate & 10.00 & & \\
Supplement 410750 & & & \\
$\quad$ (93G to 95NRC & & & \\
growth values) & & & \\
L-Arg & & & 2.00 \\
L-Met & & & \\
\hline
\end{tabular}


comparison was the pattern for mammary fat pad invasion and ductal branching typical for that of a 4-week-old mouse from our colony fed a normal diet and not from the experimental groups. The grid used to assess the development was developed using a typical 4-week-old mouse from our colony to use as a scoring template: 1, longitudinal growth from the nipple not yet reaching the lymph node; 2, growth reaching the medial edge of the lymph node; 3, growth midway past the lymph node; 4, growth to the lateral edge of the lymph node; 5, growth beyond the lymph node. To validate the use of our method of evaluation, duct lengths were measured from the nipple to the ends of the ducts.

The average ductal length from each gland was determined, and the means were combined and averaged per treatment and found to be in agreement with our methodology (Fig. 1).

DNA was extracted from approximately $100 \mathrm{mg}$ of tissue using a Mini-Prep Kit (Qiagen, Valencia, CA, USA) and measured at a wavelength of $260 / 280 \mathrm{~mm}$ on a Spectromax 250 (Molecular Device, Inc., Sunnyvale, CA, USA).

Epidermal growth factor. Quantification of EGF in the serum was performed by an enzyme-linked immunoassay with the use of kit no. BT-720 (Biomedical Technologies, Stoughton, MA, USA). For the analysis of tissue EGF, previously published procedures were followed (Kenney et al. $)^{(26)}$. A total of $150 \mathrm{mg}$ of tissue taken from the abdominal gland was homogenised in $2.5 \times 12.1 \mathrm{~g}$ Tris base, $3.7 \mathrm{~g} \mathrm{Na}_{2-}$ EDTA. $2 \mathrm{H}_{2} \mathrm{O}(\mathrm{pH} 7.4)$ and precipitated in $1.25 \mathrm{ml}$ of $10 \%$ tricarboxylic acid. Following centrifugation, the protein pellet was resuspended in $0.5 \mathrm{ml}$ of buffer with protease inhibitors, and assayed as before.

Serum oestradiol. The serum concentrations of oestradiol were measured using RIA (kit no. TKE21; Diagnostic Products Corporation, Los Angeles, CA, USA) following the manufacturer's instructions.

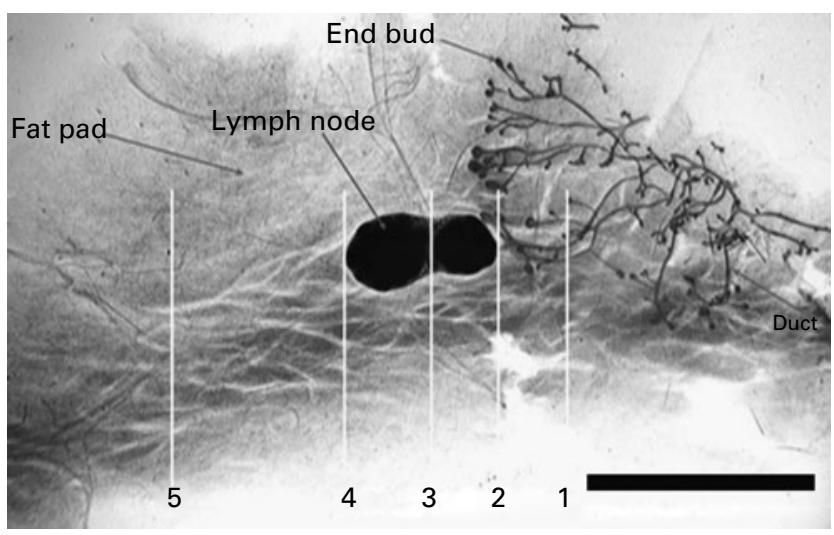

Fig. 1. Whole-mount evaluations were done by two investigators as a double-blind scoring trial, measuring outgrowth from the nipple to the lymph node. The grid used to assess the development was developed using a typical 4-week-old mouse from our colony to use as a scoring template. 1, Longitudinal growth from the nipple not yet reaching the lymph node; 2, growth reaching the medial edge of the lymph node; 3 , growth midway past the lymph node; 4 , growth to the lateral edge of the lymph node; 5 , growth beyond the lymph node. Scale bar, $0.5 \mathrm{~cm}$.

\section{Expt 2}

As a result of our findings in the wild-type strain, we examined the Her2/neu transgenic strain. The same treatments and experimental design were provided, with twelve animals for each treatment group.

\section{Statistical analyses}

For each dependent variable and experiment, individual oneway ANOVA were used and significant $F$ ratios were followed by comparisons of the group means using Tukey-Kramer multiple comparison post hoc tests. The analyses used Graph Pad Prism ${ }^{\circledR}$, Instat ${ }^{\circledR}$ (GraphPad Software, Inc., La Jolla, CA, USA) and SAS ${ }^{\circledR}$ (SAS Institute, Cary, NC, USA) software, and statistical significance was set at the $P<0.05$ level.

\section{Results}

\section{Expt 1}

There were no significant differences observed in body weights among the control and experimental groups.

Whole-mount evaluation. In the control group fed casein, most of the longitudinal ducts did not reach the lymph node (score 1). The glands of the oestradiol-treated group displayed similar longitudinal growth as observed in the control group, but there was increased collateral branching compared with the growth pattern of the control group. The most significant longitudinal growth was evident in the soya-fed group, with development well beyond the lymph node (score 5) and significantly greater than all other groups $(P<0 \cdot 05)$. The group fed $\alpha$-LA showed longitudinal development and extensive collateral branching, with a score of 3 . The variance within each treatment group was low (Table 2). Overall growth was reflected in the total DNA concentration with the highest concentration of DNA in soya or $\alpha$-LA (Fig. 2(A)). The number of terminal end buds (TEB) as well as the sparse cell population of the ECM contributed to these values (Fig. 3(A)).

\section{Expt 2}

The Her2/neu mice were generally smaller in body weight and in gland size compared with the wild type mice. There were no differences in weights among the treatment groups

Table 2. Mammary fat pad invasion for the wild-type ( $n$ 30) and mutant ( $n$ 12) strains* (Indices with their standard errors)

\begin{tabular}{|c|c|c|c|c|}
\hline \multirow[b]{2}{*}{ Diet } & \multicolumn{2}{|c|}{ Wild type } & \multicolumn{2}{|c|}{ Mutant } \\
\hline & Index & SE & Index & SE \\
\hline Control & $1 \cdot 30^{a}$ & 0.51 & $2 \cdot 3^{a}$ & 0.51 \\
\hline Oestrogen & $1.56^{\mathrm{a}}$ & 0.64 & $4 \cdot 0^{\mathrm{b}}$ & 0.64 \\
\hline$\alpha$-Lactalbumin & $3 \cdot 29^{b}$ & 1.01 & $5 \cdot 0^{c}$ & 0.11 \\
\hline Soya & $4 \cdot 90^{c}$ & 0.30 & $4 \cdot 0^{\mathrm{b}}$ & 0.30 \\
\hline
\end{tabular}


(A)

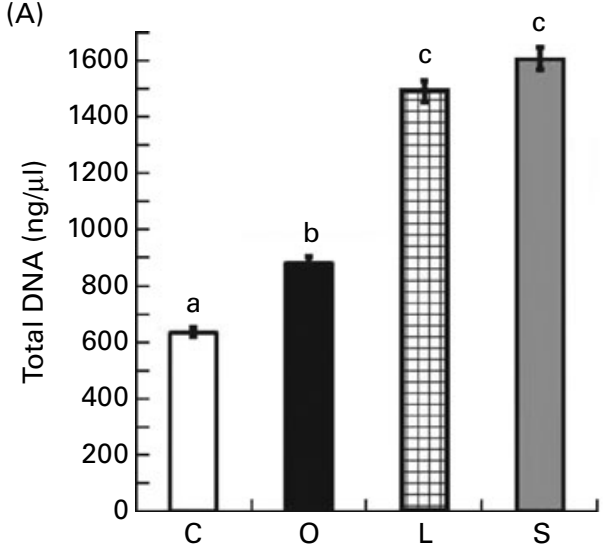

(B)

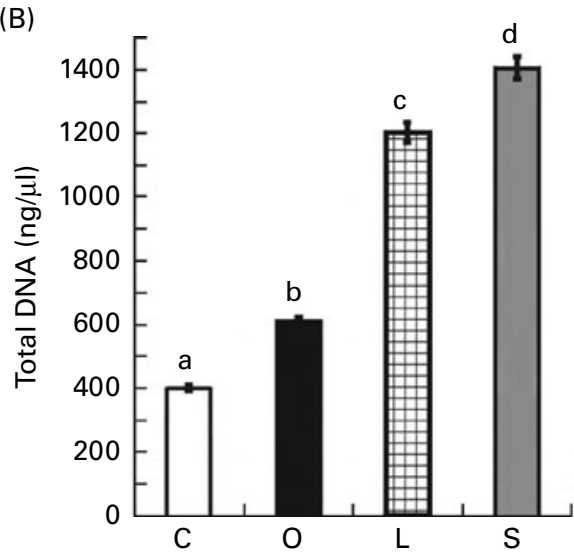

Fig. 2. (A) Mean concentrations of total DNA from mammary tissue $(\mathrm{ng} / \mu \mathrm{l})$ for all treatment groups $(n 30)$ for the CD1 strain in Expt 1. (B) Mean concentration for total DNA for the Her2/neu strain ( $n$ 12). DNA was extracted and absorbance read at $260 / 280 \mathrm{~nm}$. Values are means, with their standard errors represented by vertical bars. ${ }^{a, b, c, d}$ Mean values with unlike letters were significantly different $(P<0.05)$. C, casein control; O, oestrogen; L, $\alpha$-lactalbumin; $\mathrm{S}$, soya.

either at the onset or at the completion of the experiment. Even so, the same criteria for evaluation were used. The groups treated with soya (score 4) or oestrogen (score 4) had significantly $(P<0.05)$ more growth than the control (score 2.3). $\alpha$-LA had the greatest longitudinal growth (score 5; Table 2). Overall growth was reflected in the total DNA concentration with the highest concentration of DNA in soya or $\alpha$-LA.

In the wild-type mice, obvious TEB were evaluated and showed the following: the groups fed soya and $\alpha$-LA provided significantly increased numbers of TEB compared with the casein-fed controls or the group treated with oestradiol. A similar pattern was observed with the group fed $\alpha$-LA. When compared with the controls, the complex branching pattern from the oestradiol treatment resulted in a greater number of TEB. In Her2/neu mice, all treatments resulted in significantly increased $(P<0 \cdot 001)$ TEB when compared with the control. The highest numbers were found in the oestrogen group followed by the soya group, which in turn was followed by the $\alpha$-LA group (Fig. 3(B)).

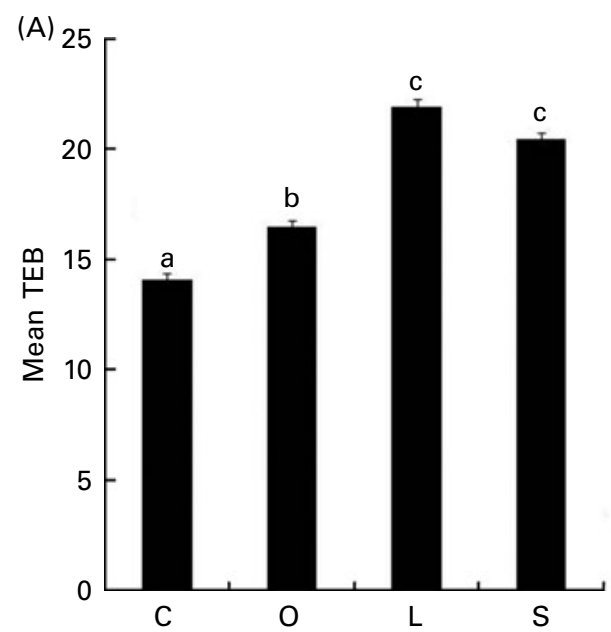

\section{Extracellular matrix}

Our interest was in relative values rather than absolute values for each protein. Therefore, using the absolute values for the control group, we set up ratios of matrix metalloproteinase-2 $\left(\mathrm{MMP}_{2}\right)$ :tissue inhibitor of $\mathrm{MMP}_{2}\left(\mathrm{TIMP}_{2}\right)$ to be equal to 1 and compared all experimental values with the control. A ratio greater than 1 suggested evidence that there was a treatment effect that disrupted the balance between the two proteins. As indicated by the results (Table 3 and Fig. 4), the $\alpha$-LA- and soya-fed groups had the greatest differences $(P<0.05)$ when compared with the control or the oestradiol treatment groups in favour of degradation. The more dramatic overall effects were observed in the mutants compared with the wild types, although the trends were similar.

\section{Oestrogen}

No significant differences were observed in the serum concentrations of oestradiol in the groups fed casein (control), $\alpha$-LA or soya. In the oestradiol-treated group, values were

(B)

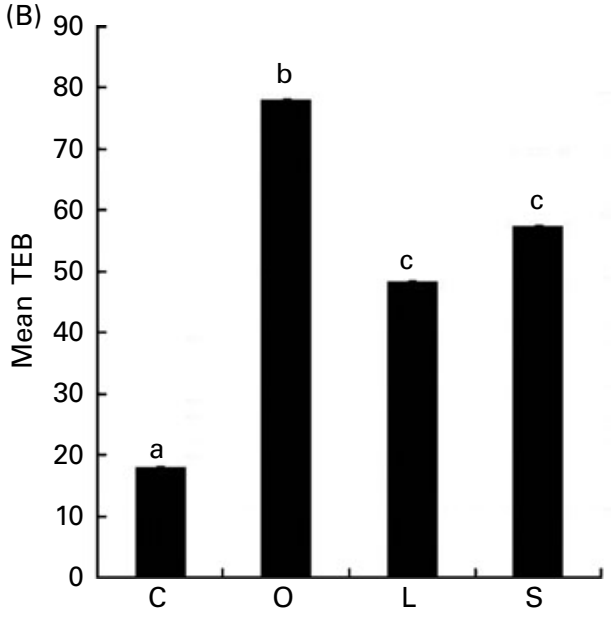

Fig. 3. Prominent buds were counted per gland and designated as terminal end buds (TEB). Counting was done by two investigators as a double-blind trial. Values are means of total TEB for $(A)$ wild type and $(B)$ mutant mice from all treatment groups, with their standard errors represented by vertical bars. ${ }^{a, b, c}$ Mean values with unlike letters were significantly different $(P<0.05)$. C, casein control; O, oestrogen; $L$, $\alpha$-lactalbumin; $S$, soya. 
Table 3. Ratios of matrix metalloproteinase-2 $\left(\mathrm{MMP}_{2}\right)$ :tissue inhibitor of $\mathrm{MMP}_{2}\left(\mathrm{TIMP}_{2}\right)$ for all groups based on raw absorbance mean values of the respective immunoassays*

\begin{tabular}{lcc}
\hline Diet & Wild type & Mutant \\
\hline Control & $1 \cdot 0^{\mathrm{a}}$ & $1 \cdot 0^{\mathrm{a}}$ \\
Oestrogen & $0 \cdot 88^{\mathrm{a}}$ & $1 \cdot 10^{\mathrm{a}}$ \\
$\alpha$-Lactalbumin & $1 \cdot 78^{\mathrm{b}}$ & $2 \cdot 23^{\mathrm{b}}$ \\
Soya & $1 \cdot 19^{\mathrm{a}}$ & $2 \cdot 07^{\mathrm{b}}$ \\
\hline a,b Mean values within a column with unlike superscript letters were significantly \\
different $(P<0 \cdot 05)$.
\end{tabular}

significantly less $(P<0.05)$ by approximately $35 \%$ when compared with the other three groups in both the wild-type and mutant strains (Fig. 5(A) and (B)).

\section{Epidermal growth factor}

It is well documented that the interaction of oestrogen and EGF is dependent on the developmental state of the mammary gland. Because soya has oestrogenic effects, the question was whether concentrations of EGF in the tissue could be influenced by treatment other than oestrogen. Our results demonstrate that concentrations of EGF in the wild-type mammary tissue are not only increased by oestrogen and soya, but to a greater extent by $\alpha$-LA $(P<0 \cdot 01)$ when compared with the control (Fig. 6(A)). In the mutant strain, soya had little effect when compared with the control (Fig. 6(B)). However, both oestrogen and $\alpha$-LA significantly increased the tissue concentration of EGF $(P<0 \cdot 05)$

\section{Discussion}

As in agreement with other studies ${ }^{(25)}$, we found that soya as a treatment did not alter body weights in either strain. There were also no effects of our other treatments at the end of $7 \mathrm{~d}$. The critical period for the effects of the administration of chemical carcinogens in rodents is between days 45 and 52 of age. It is at this time the TEB divide actively and thereby are most susceptible to transformation ${ }^{(14)}$. Dietary soya is most effective in decreasing mammary cancer incidence if consumed during pre-pubertal development ${ }^{(15)}$. The premise is that if the gland can structurally differentiate, fewer mitotic cells are available for transformation. Similar findings using milk and its derivatives have been demonstrated in human longitudinal studies. In the present study, we administered a short-term $(7 \mathrm{~d})$ treatment regimen to weaned female mice, before puberty, to examine changes in gland morphology and key ECM proteins using two separate mouse models. From weaning day 21 to termination day 28 , there should be little endogenous oestrogen to confound the results. As demonstrated by other dietary studies ${ }^{(1,2,15)}$, we found that soya and $\alpha$-LA can affect growth and maturation of the prepubertal mammary gland. In order for ductal elongation to occur, there has to be deconstruction and reconstruction of the ECM to allow growth and support, respectively. The scaffolding that supports the mammary gland was also affected by treatment. Collagens are the major components of the ECM, and degradation of the ECM by MMP is necessary for ductal elongation. The balance between MMP activity and MMP inhibition provides coordinated growth and development of the mammary gland. In contrast, MMP degradation may occur without consequent action of the inhibitors. On the other hand, high inhibitory activity is reflected by low MMP activity. We examined $\mathrm{MMP}_{2}$ because of its action on collagen degradation in the mammary gland during the period before puberty. TIMP $_{2}$ was measured because it degrades $\mathrm{MMP}_{2}$. With dietary soya and $\alpha$-LA, we observed the highest number of TEB in addition to the most longitudinal growth in the wild type. However, the effects of the treatments on the TEB differed in the mutant strain. The $\mathrm{MMP}_{2}$ : $\mathrm{TIMP}_{2}$ ratio was highest
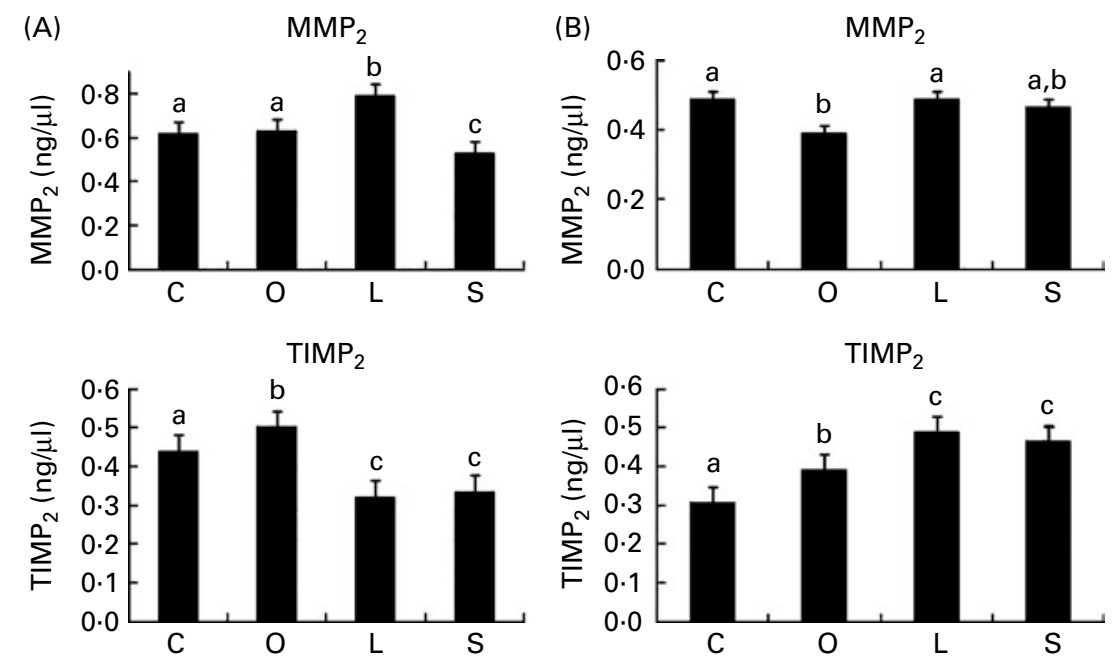

Fig. 4. Quantification of matrix metalloproteinase-2 $\left(\mathrm{MMP}_{2}\right)$ and tissue inhibitor of $\mathrm{MMP}_{2}\left(\mathrm{TIMP}_{2}\right)$ as determined by immunoassay. Total proteins were extracted from $150 \mathrm{mg}$ of tissue from the abdominal glands using tricarboxylic acid precipitation. Specific proteins were evaluated using manufacturers' guidelines as described in Methods (ng/ml). Each sample was plated in triplicate. Values are mean concentrations, with their standard errors represented by vertical bars. ${ }^{a, b, c}$ Mean values with unlike letters were significantly different $(P<0.05)$. (A) Wild type $(n 30)$ and $(B)$ mutant. C, casein control; O, oestrogen; L, $\alpha$-lactalbumin; $S$, soya. 

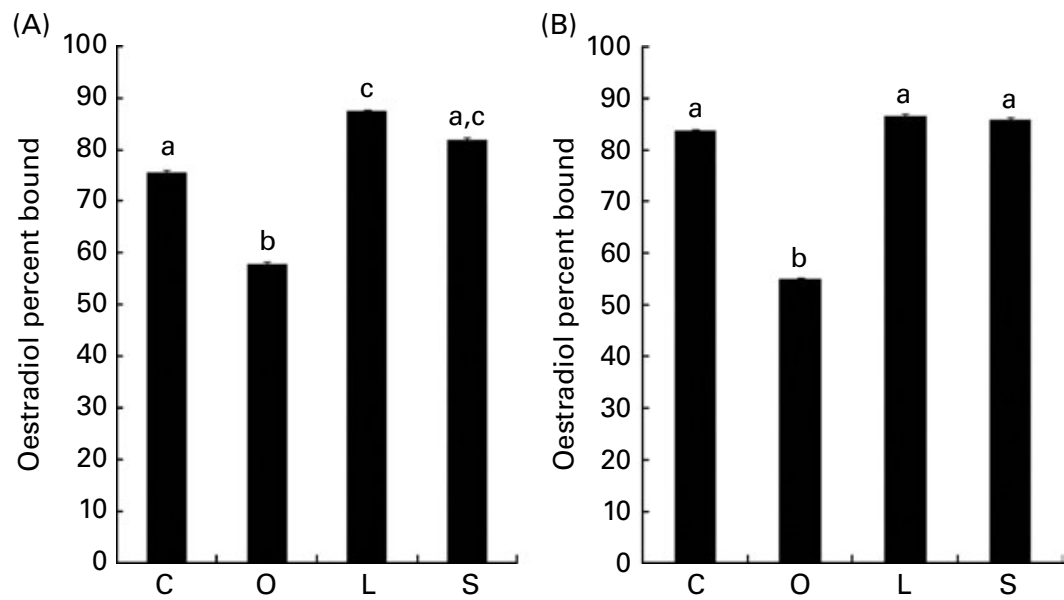

Fig. 5. RIA was done to measure serum oestradiol $(\mathrm{pg} / \mathrm{ml})$. Some samples from each group/strain were pooled to assure sufficient quantities. Concentrations of oestradiol in the oestradiol benzoate-treated group for both (A) wild type $(n 10)$ and (B) mutant $(n$ 8) were significantly less than all other groups (control (C), $\alpha$-lactalbumin (L) and soya (S)) by $35 \%$. Values are means, with their standard errors represented by vertical bars. ${ }^{a, b, c}$ Mean values with unlike letters were significantly different $(P<0.05)$. O, oestrogen.

for $\alpha$-LA, supporting the elongation; however, there were fewer TEB compared with the soya- and oestradiol-treated groups. The use of total DNA accounted not only for the action in the epithelial cells but also for the cells associated with the stroma. In parallel, the group fed $\alpha$-LA displayed a similar pattern of growth that also included secondary and tertiary ductal growth. This pattern suggested that changes in the ECM were affected to allow both longitudinal and collateral ductal growth. The highest ratio observed between $\mathrm{MMP}_{2}$ and TIMP 2 in the groups fed $\alpha$-LA and soya would suggest that the balance was in favour of degradation to provide a pathway for growth and elongation to occur. The results reflect those of others who found that ductal elongation resulted in changes in the balance of degradation and inhibition $^{(22,27)}$. The longitudinal and collateral ductal growth suggests an interaction of the epithelial cells and the ECM. Comparison of the $\mathrm{MMP}_{2}$ : $\mathrm{TIMP}_{2}$ ratios supports this result.

A relationship between the ECM and EGF has been established ${ }^{(24)}$. The protein composition of the ECM regulates the response to EGF related to gene expression ${ }^{(25)}$. In addition, EGF modulates the adhesion of tumour cells to ECM proteins ${ }^{(27)}$. EGF is important in early development, relating epithelial to mesenchymal transition. Interestingly, despite the action of $\alpha$-LA on increasing serum concentrations of EGF, $\alpha$-LA did not alter the concentrations of oestradiol in the serum, suggesting that the action of $\alpha$-LA on the mammary gland was not through oestrogen directly. This result may have more to do with the negative feedback mechanism by exogenous oestrogen at the level of the hypothalamus than any influence of EGF. To our knowledge, there are no studies linking an interaction between $\alpha$-LA and EGF. There are several considerations of the effects of $\alpha$-LA as it relates to mammary gland development and EGF. The first consideration is that a specific digested fragment of whey milk protein is similar to EGF and is recognised by the EGF receptor. This possibility is plausible, as it is known that fragments of milk proteins including $\alpha$-LA are biologically active ${ }^{(28,29)}$. The second, and possibly the more feasible explanation, is that
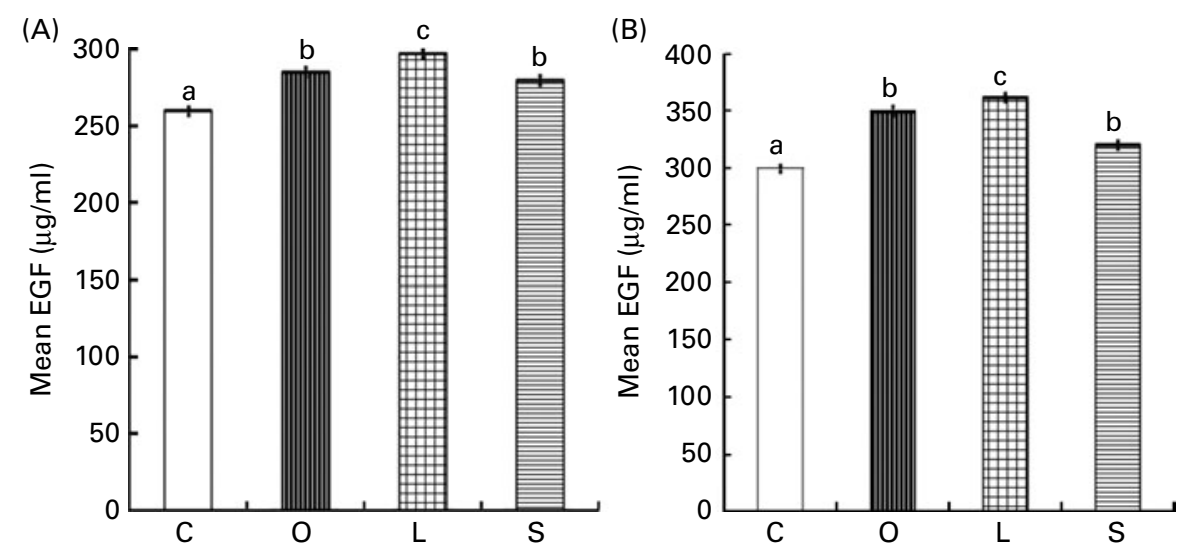

Fig. 6. Quantification of epidermal growth factor (EGF) concentrations $(\mu \mathrm{g} / \mathrm{ml})$ in mammary tissues. Total proteins were extracted from $150 \mathrm{mg}$ of tissue from the abdominal glands using tricarboxylic acid precipitation. There was no separation of epithelia and stroma. Individual samples were plated in triplicate. The standard used was the mouse EGF extracted from serum and commercially available. Values are means, with their standard errors represented by vertical bars. ${ }^{a, b, c}$ Mean values with unlike letters were significantly different $(P<0.05)$. (A) Wild type $(n 10)$ and $(\mathrm{B})$ mutant $(n 8)$. C, casein control; O, oestrogen; L, $\alpha$-lactalbumin; $\mathrm{S}$, soya. 
$\alpha$-LA or its digested fragments may also serve to facilitate the synthesis and/or the activity of EGF in the mammary tissue or in other tissues to increase the serum concentration, which in turn may mediate oestrogenic response in the stroma and epithelia of the mammary gland. If this were the case, it would support the findings of others ${ }^{(27)}$.

\section{Conclusion}

The premise that soya has protective effects on mammary cancer development is based on its inclusion in the diet of Asian women before puberty. Similar inverse correlations of milk consumption and tumour incidence have been demonstrated for human diets. The caveat is to recognise that lifestyle, genetics, age, stage of development of the mammary gland and the total diet are all factors in the environmental milieu promoting tumour development. We have demonstrated that the whey milk protein $\alpha$-LA can affect the morphology of the mammary gland. Whereas soya may work directly on the epithelial cells via stem cells or through the proteins of an intracellular pathway, $\alpha$-LA appears to modulate the activity of ECM proteins in newly weaned mice after only 1 week of dietary supplement. $\alpha$-LA may possibly promote the activity of EGF; however, this suggestion is inconclusive based on our data. If this protein allows the gland to grow and differentiate before the critical period of tumour initiation, then including milk products in the diet at an early age may have implications in the intervention or prolonging the latency of mammary tumour development in later life.

\section{Acknowledgements}

The authors wish to thank William Swallow and Joy Smith, Department of Statistics, North Carolina State University. The authors would also like to thank the many undergraduate students who assisted. The present study was funded by the North Carolina Institute of Nutrition, North Carolina Nutrition Association, North Carolina Dairy Foundation and North Carolina Agricultural and Research Station. None of the authors has conflicts of interests. B. A.-M. contributed to the experimental design, experimental procedures, data interpretation and manuscript writing. J. J. L. contributed to the experimental design, experimental procedures and data interpretation. C. A. M. contributed to the experimental procedures, data analysis, data interpretation and manuscript writing.

\section{References}

1. Lamartiniere CA (2000) Protection against breast cancer with genistein: a component of soy. Am J Clin Nutr $\mathbf{7 1}$, 1705S-1707S, discussion 8S-9S.

2. Cotroneo MS, Wang J, Fritz WA, et al. (2002) Genistein action in the prepubertal mammary gland in a chemoprevention model. Carcinogenesis 23, 1467-1474.

3. van't Veer P, Kok FJ, Hermus RJ, et al. (1989) Alcohol dose, frequency and age at first exposure in relation to the risk of breast cancer. Int J Epidemiol 18, 511-517.

4. Murata M, Midorikawa K, Koh M, et al. (2004) Genistein and daidzein induce cell proliferation and their metabolites cause oxidative DNA damage in relation to isoflavone-induced cancer of estrogen-sensitive organs. Biochemistry $\mathbf{4 3}$, 2569-2577.

5. Allred CD, Allred KF, Ju YH, et al. (2004) Dietary genistein results in larger MNU-induced, estrogen-dependent mammary tumors following ovariectomy of Sprague-Dawley rats. Carcinogenesis 25, 211-218.

6. Petrakis NL, Barnes S, King EB, et al. (1996) Stimulatory influence of soy protein isolate on breast secretion in preand postmenopausal women. Cancer Epidemiol Biomarkers Prev 5, 785-794

7. Messina M \& Wu AH (2009) Perspectives on the soy-breast cancer relation. Am J Clin Nutr 89, 1673S-1679S.

8. Bounous G, Batist G \& Gold P (1991) Whey proteins in cancer prevention. Cancer Lett 57, 91-94.

9. Hakkak R, Korourian S, Shelnutt SR, et al. (2000) Diets containing whey proteins or soy protein isolate protect against 7,12dimethylbenz $(a)$ anthracene-induced mammary tumors in female rats. Cancer Epidemiol Biomarkers Prev 9, 113-117.

10. Knekt P, Jarvinen R, Seppanen R, et al. (1996) Intake of dairy products and the risk of breast cancer. $\mathrm{Br} J$ Cancer $\mathbf{7 3}$, 687-691.

11. Hjartaker A, Laake P \& Lund E (2001) Childhood and adult milk consumption and risk of premenopausal breast cancer in a cohort of 48,844 women - the Norwegian women and cancer study. Int J Cancer 93, 888-893.

12. Thompson PA, Gutkind JS, Robbins KC, et al. (1992) Identification of distinct populations of PI-3 kinase activity following T-cell activation. Oncogene 7, 719-725.

13. Alston-Mills B, Hepler CD, Sternhagen L, et al. (1998) Alphalactalbumin as a modulator of mammary cellular activity. In vitro Cell Dev Biol Anim 34, 747-750.

14. Hakansson A, Andreasson J, Zhivotovsky B, et al. (1999) Multimeric alpha-lactalbumin from human milk induces apoptosis through a direct effect on cell nuclei. Exp Cell Res 246, 451-460.

15. Nielsen TS, Khan G, Davis J, et al. (2011) Prepubertal exposure to cow's milk reduces susceptibility to carcinogen-induced mammary tumorigenesis in rats. Int $J$ Cancer 128, $12-20$.

16. Cardiff RD \& Wellings SR (1999) The comparative pathology of human and mouse mammary glands. J Mammary Gland Biol Neoplasia 4, 105-122.

17. Russo J, Lynch H \& Russo IH (2001) Mammary gland architecture as a determining factor in the susceptibility of the human breast to cancer. Breast J 7, 278-291.

18. Wiseman BS \& Werb Z (2002) Stromal effects on mammary gland development and breast cancer. Science 296, 1046-1049.

19. Bissell MJ \& Radisky D (2001) Putting tumours in context. Nat Rev Cancer 1, 46-54.

20. Alford D \& Taylor-Papadimitriou J (1996) Cell adhesion molecules in the normal and cancerous mammary gland. J Mammary Gland Biol Neoplasia 1, 207-218.

21. Maffini MV, Soto AM, Calabro JM, et al. (2004) The stroma as a crucial target in rat mammary gland carcinogenesis. $J$ Cell Sci 117, 1495-1502.

22. Weaver VM \& Gilbert P (2004) Watch thy neighbor: cancer is a communal affair. J Cell Sci 117, 1287-1290.

23. Guy CT, Webster MA, Schaller M, et al. (1992) Expression of the neu protooncogene in the mammary epithelium of transgenic mice induces metastatic disease. Proc Natl Acad Sci U S A 89, 10578-10582.

24. Revillion F, Bonneterre J \& Peyrat JP (1998) ERBB2 oncogene in human breast cancer and its clinical significance. Eur J Cancer 34, 791-808. 
25. Jin Z \& MacDonald RS (2002) Soy isoflavones increase latency of spontaneous mammary tumors in mice. $J$ Nutr 132, 3186-3190.

26. Kenney NJ, Bowman A, Korach KS, et al. (2003) Effect of exogenous epidermal-like growth factors on mammary gland development and differentiation in the estrogen receptor-alpha knockout (ERKO) mouse. Breast Cancer Res Treat 79, 161-173.

27. Woodward TL, Xie J, Fendrick JL, et al. (2000) Proliferation of mouse mammary epithelial cells in vitro: interactions among epidermal growth factor, insulin-like growth factor I, ovarian hormones, and extracellular matrix proteins. Endocrinology 141, 3578-3586.

28. Wiseman BS, Sternlicht MD, Lund LR, et al. (2003) Sitespecific inductive and inhibitory activities of MMP-2 and MMP-3 orchestrate mammary gland branching morphogenesis. J Cell Biol 162, 1123-1133.

29. Grant MR, Hunt CA, Xia L, et al. (2004) Modeling mammary gland morphogenesis as a reaction-diffusion process. Conf Proc IEEE Eng Med Biol Soc 1, 679-682. 